\title{
lodine I 131 Monoclonal Antibody 3F8
}

National Cancer Institute

\section{Source}

National Cancer Institute. Iodine I 131 Monoclonal Antibody 3F8. NCI Thesaurus. Code C2431.

A radioimmunoconjug ate consisting of $3 \mathrm{~F} 8$, a murine anti-GD2 gang lioside monoclonal antibody labeled with iodine 131 (I-131), with radioimaging and radioimmunotherapeutic properties. Using monoclonal antibody 3F8 as a carrier for I-131 results in the targeted imaging and/or destruction of cells expressing GD2. GD2 is a ganglioside which is overexpressed in malignant melanoma, neuroblastoma, and small cell carcinoma of the lung. ( $\mathrm{NCl04)}$ 